\title{
TLH versus TAH: a 2 year retrospective comparative study
}

\author{
Anju Dogra*, Vinay Kumar, Nishu Bhushan
}

Department of Obstetrics and Gynecology, SMGS Hospital, Government Medical College, Jammu, J\&K, India

Received: 26 June 2019

Revised: 09 September 2019

Accepted: 13 September 2019

\section{*Correspondence:}

Dr. Anju Dogra,

E-mail: anjudogra57212@gmail.com

Copyright: () the author(s), publisher and licensee Medip Academy. This is an open-access article distributed under the terms of the Creative Commons Attribution Non-Commercial License, which permits unrestricted non-commercial use, distribution, and reproduction in any medium, provided the original work is properly cited.

\begin{abstract}
Background: Laparoscopic hysterectomy has become a widely accepted technique worldwide, since its introduction by Reich in 1989. The aim of the study was to compare the surgical results and intra- operative and post-operative complications between total laparoscopic hysterectomy (TLH) and total abdominal hysterectomy (TAH).

Methods: Authors conducted a retrospective study at SMGS hospital, GMC Jammu between October 2016 to September 2018, 126 patients who underwent TLH and 126 patients who underwent TAH, were included.

Results: Authors observed that there was no significant difference between the two groups in respect to patient's age, parity and indication of surgery. Duration of surgery was found to be longer in TLH than TAH. The length of hospital stay was less in TLH than TAH. Hb drop was more in TAH group. 25 patients of TAH were given post op blood transfusion but only 9 patients of TLH were given post op blood transfusion. The time to ambulation in patients of TLH was much shorter than TAH. Wound infection was more common in TAH as compared to TLH, 5 patients had wound infection and in 4 patients resuturing was done for wound dehiscence. In 8 patients laparoscopy was converted to laparotomy because of adhesions, vascular injury and in one case because of bowel injury.

Conclusions: This study showed that TLH can be safely performed by the experienced surgeon as an alternative to abdominal hysterectomy. It offers several benefits over TAH such as smaller incision, earlier ambulation, shorter hospital stay, faster recovery time and does not increase more serious complications than TAH.
\end{abstract}

Keywords: Complications, Efficacy, Hospital stay, Total abdominal hysterectomy, Total laparoscopic hysterectomy, Outcome

\section{INTRODUCTION}

Hysterectomy is one of the most common gynecological surgery. ${ }^{1-3}$ Hysterectomy can be performed by abdominal, vaginal and laparoscopic method. Abdominal hysterectomy has been the most popular method but it is more invasive and is associated with more blood loss, delayed recovery and longer hospital stay. Roul palmer in Paris in 1944 made first report on laparoscopy within the female pelvis. ${ }^{4-6}$ And then total laparoscopic hysterectomy was introduced by Reich in 1989. Since then it has become a worldwide technique. Laparoscopic hysterectomy was reported to have lower post operative morbidity, improved quality of life, shorter hospital stay and less blood loss when compared to laparotomy. ${ }^{7,8}$

Laparoscopic approach may not be feasible in patients with history of multiple abdominal surgery, dense pelvis/bowel adhesions and large fibroids where laparotomy takes the lead.

The aim of this study was to compare the intra and postoperative results of Total abdominal hysterectomy (TAH) and total laparoscopic hysterectomy (TLH). 


\section{METHODS}

A retrospective comparative study was carried out in SMGS hospital, GMC Jammu from October 2016 to September 2018 (2 years). The study included 126 patients who underwent TLH with or without salpingooopherectomy (SO or BSO) for various indications and they were compared with 126 control patients who underwent TAH with or with salpingo-oopherectomy (SO or BSO). The data were obtained from theatre register and was verified via a detailed review of medical records.

\section{Inclusion criteria}

- Patients included in this study were selected by uterine size not larger than 12 weeks of gestation, no cardiac or pulmonary disease, no contraindication of laparoscopic surgery.

\section{Exclusion criteria}

- $\quad$ Patients with malignant disease and fused hip joint.

The factors examined include demographic details, indication of surgery, intra operative details, duration of surgery, $\mathrm{Hb}$ drop, ambulation, post-operative complications like secondary haemorrhage, DVT, ileus, febrile morbidity, wound infection and resuturing, post op stay, post op blood transfusion and conversion to laparotomy in case of TLH.

The duration of operation was calculated from the first skin incision for the Veress needle insertion to the last suture of abdominal wound.

Febrile morbidity was defined as an oral temperature of $100.4^{\circ} \mathrm{F} / 38.0^{\circ} \mathrm{C}$ or higher, excluding the first 24 hours postoperatively. Duration of hospital stay was calculated from the day of surgery to the day of discharge. Patients were discharged when they were afebrile, with normal voiding, and off analgesic.

\section{Statistical analysis}

Data were presented as mean and SD or percentage. A statistical analysis of the data was performed using unpaired student's t-test, fisher's exact test and chisquare test. P-value $<0.05$ was considered statistically significant.

\section{RESULTS}

The distribution of patients according to age and parity is shown in Table 1 . The mean age $(45.73 \pm 6.4$ versus $45.16 \pm 4.5$ years $)$ and mean parity $(4.32 \pm 2.08$ versus $4.77 \pm 3.08$ ) for the TLH and TAH groups respectively were comparable with no significant difference. The indications of surgery (Table 2) were not significantly different in both groups. Most common indication in both the groups was fibroid uterus followed by AUB-N.
Table 1: Distribution of patients according to age and parity.

\begin{tabular}{|llll|}
\hline & TLH & TAH & P-value \\
\hline Age (years) & $45.16 \pm 4.58$ & $45.23 \pm 6.44$ & 0.321 \\
\hline Parity & $4.32 \pm 2.08$ & $4.77 \pm 3.08$ & 0.171 \\
\hline
\end{tabular}

Table 2: Distribution of patients according to indication of surgery.

\begin{tabular}{|lll|}
\hline Indication & TLH No. $(\%)$ & TAH No. (\%) \\
\hline Fibroid & $53(42.06 \%)$ & $69(54.76 \%)$ \\
\hline $\begin{array}{l}\text { Endometrial } \\
\text { hyperplasia }\end{array}$ & $10(7.93 \%)$ & $11(8.73 \%)$ \\
\hline Ovarian cyst & $10(7.93 \%)$ & $9(7.14 \%)$ \\
\hline Adenomyosis & $11(8.73 \%)$ & $5(3.96 \%)$ \\
\hline AUB-N & $26(20.63 \%)$ & $15(11.90 \%)$ \\
\hline Others & $16(12.69 \%)$ & $17(13.49 \%)$ \\
\hline Total & $\mathbf{1 2 6}(\mathbf{1 0 0 \%})$ & $\mathbf{1 2 6}(\mathbf{1 0 0 \%})$ \\
\hline
\end{tabular}

Table 3: Distribution according to intra operative and post operative complications.

\begin{tabular}{|c|c|c|c|c|}
\hline & & $\begin{array}{l}\text { TLH } \\
\text { No. }\end{array}$ & $\begin{array}{l}\text { TAH } \\
\text { No. }\end{array}$ & P-value \\
\hline \multirow[t]{4}{*}{$\begin{array}{l}\text { Intra } \\
\text { operative }\end{array}$} & $\begin{array}{l}\text { Bladder } \\
\text { injury }\end{array}$ & 1 & 2 & \multirow{4}{*}{0.12} \\
\hline & $\begin{array}{l}\text { Ureteric } \\
\text { injury }\end{array}$ & 0 & 0 & \\
\hline & Bowel injury & 1 & 0 & \\
\hline & $\begin{array}{l}\text { Vascular } \\
\text { injury }\end{array}$ & 2 & 0 & \\
\hline \multirow[t]{7}{*}{$\begin{array}{l}\text { Post } \\
\text { operative }\end{array}$} & $\begin{array}{l}\text { Secondary } \\
\text { hemorrhage }\end{array}$ & 1 & 0 & \multirow{7}{*}{$<0.0001$} \\
\hline & 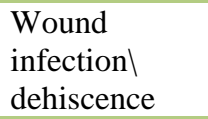 & 0 & 5 & \\
\hline & Resuturing & 0 & 4 & \\
\hline & Ileus & 1 & 4 & \\
\hline & $\begin{array}{l}\text { Febrile } \\
\text { morbidity }\end{array}$ & 1 & 2 & \\
\hline & DVT & 0 & 0 & \\
\hline & $\begin{array}{l}\text { Conversion to } \\
\text { laprotomy }\end{array}$ & 8 & - & \\
\hline
\end{tabular}

In 8 patients conversion of TLH to laparotomy was done (due to dense adhesion in 5 cases, due to vascular injury in 2 and bowel injury in 1 case). It was observed that 4 patients of TLH group had major intra operative complications (Table 3) while only 2 patients in TAH group. Amongst major complications in TLH group, 1 patient had bladder injury and the bladder was repaired, one patient had bowel injury which was diagnosed intraoperatively and laparoscopy was converted to laparotomy and 2 patients had vascular injury. In TAH group 2 patients had bladder injury. Secondary haemorrhage occurred in 1 patient in TLH group which was managed conservatively, while TAH group had none. Ileus occurred in 1 patient in TLH while 4 patients in TAH had 
ileus. None of the patients in TLH had wound infection while 5 patients in TAH group had wound infection, in which 4 had wound dehiscence and resuturing was done. Febrile morbidity was noted in 1 patient in TLH versus 2 in TAH.

Table 4: Distribution of patients according to $\mathrm{Hb}$ drop and post op blood transfusion.

\begin{tabular}{|llll|}
\hline & TLH & TAH & P-value \\
\hline HB drop $(\mathrm{g} \%)$ & $1.46 \pm 0.64$ & $1.83 \pm 0.68$ & $<0.0001$ \\
\hline $\begin{array}{l}\text { Post operative } \\
\text { blood transfusion }\end{array}$ & $9(7.14 \%)$ & $25(19.8 \%)$ & $<0.0001$ \\
\hline
\end{tabular}

Table 5: Distribution of patients according to duration of surgery and ambulance (hours) from surgery.

\begin{tabular}{|c|c|c|c|}
\hline & $\begin{array}{l}\text { TLH } \\
(\text { mean+SD) }\end{array}$ & $\begin{array}{l}\text { TAH } \\
(\text { mean+SD) }\end{array}$ & P-value \\
\hline $\begin{array}{l}\text { Time duration } \\
\text { (minutes) }\end{array}$ & $116.02 \pm$ & $83.18 \pm 21.40$ & $<0.0001$ \\
\hline $\begin{array}{l}\text { Ambulance } \\
\text { (hours) }\end{array}$ & $9.94 \pm 4.29$ & $23.03 \pm 1.28$ & $<0.0001$ \\
\hline
\end{tabular}

It was observed that mean $\mathrm{Hb}$ drop (Table 4) was more in TAH group $(1.8 \pm 0.68 \mathrm{~g} \%)$ as compared to TLH group $(1.46 \pm 0.64 \mathrm{~g} \%)$. And the difference was statistically significant. Post op blood was transfused (Table 4) in 25 patients in TAH group while only 9 patients received blood in TLH group. In TLH group, the operative time (Table 5) was significantly longer than in TAH group (116.02 \pm 16.3 versus $83.18 \pm 21.4$ monts). The mean ambulation time (Table 5) in TLH (9.94 \pm 4.2 hours) is shorter as compared to TAH $(23.03 \pm 1.28$ hours $)$. Mean duration of hospital stay (Table 6, Figure 1) for TLH group was $(3.38 \pm 1.7$ days $)$ whereas mean duration in TAH was (7.52 \pm 3.3 days) and the difference is statistically significant.

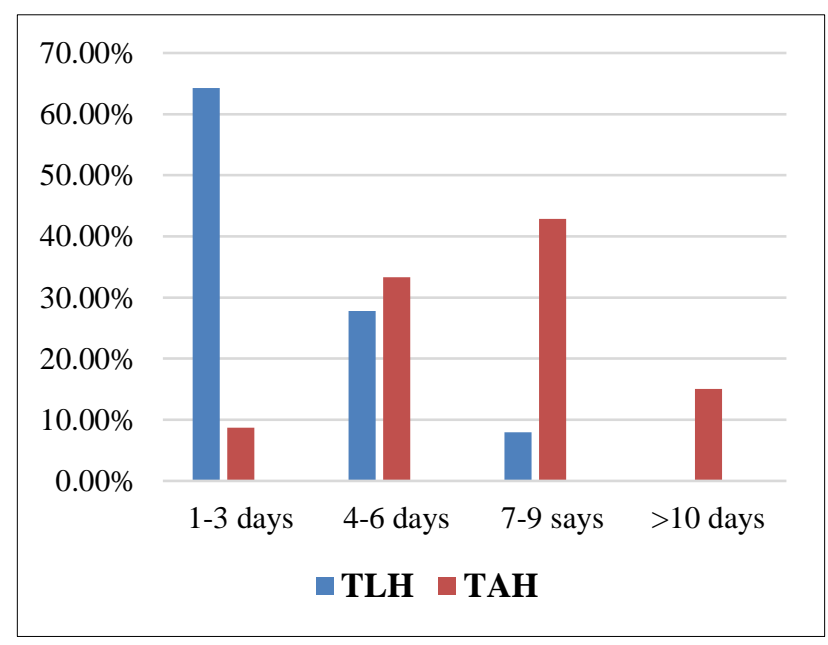

Figure 1: Hospital stay of patients (\%) in TLH versus TAH.
Table 6: Distribution of patients according to hospital stay.

\begin{tabular}{|c|c|c|c|}
\hline Days & TLH No. (\%) & TAH No. (\%) & P-value \\
\hline $1-3$ & $81(64.28 \%)$ & $11(8.73 \%)$ & \multirow{4}{*}{$<0.0001$} \\
\hline $4-6$ & $35(27.78 \%)$ & $42(33.33 \%)$ & \\
\hline $7-9$ & $10(7.93 \%)$ & $54(42.85 \%)$ & \\
\hline$>10$ days & nil & $19(15.07 \%)$ & \\
\hline
\end{tabular}

\section{DISCUSSION}

In this study there is homogeneity among demographic characters in regards to their age and parity. The mean age of the patients in TLH group was $45.73 \pm 6.4$ versus $45.16 \pm 4.5$ years in TAH group. Similar findings were reported by Loh et al, Shrestha et al and Kanmani M et al in their study. ${ }^{9-11}$ The difference observed in both groups in terms of parity was insignificant. The most common indications for surgery were fibroid uterus followed by AUB-N.

In the present study the mean surgical time taken for laparoscopic hysterectomy (116.02 \pm 16.3 months) was longer when compared to abdominal hysterectomy (83.18 \pm 21.4 months), which was statistically significant(p value 0.003 ). Similar finding was shown in their studies by Garry et al, Shrestha et al and Kanmani M et al.,10,11 likewise in study by Loh et al, the mean duration was 159 months in TLH and 98 months in TAH group. ${ }^{9}$ In our study, the mean ambulation time for TLH group is shorter than TAH group $(9.94 \pm 4.29$ versus $23.03 \pm 1.28)$, that was statistically significant ( $\mathrm{p}$ value $<0.0001$ ). Shrestha et al in their study showed the mean post op mobilisation time for TLH was $1.6 \pm 0.6$ days and $2.1 \pm 0.5$ days for TAH. ${ }^{10} \mathrm{Hb}$ drop was calculated as difference in pre-operative and post-operative hb (day 2). Mean $\mathrm{Hb}$ drop in our study was $1.4 \pm 0.6 \mathrm{~g} \%$ for TLH and $1.8 \pm 0.6 \mathrm{~g} \%$ for TAH group. These were compared and found to be statistically significant ( $p$ value $<0.0001$ ). These results were similar with the results of Pernio et al, they observed significant difference in $\mathrm{Hb}$ drop in both groups. ${ }^{12}$ Whereas in study by Marana $\mathrm{R}$ et al, the $\mathrm{Hb}$ drop in both groups didn't have significant difference. ${ }^{13}$ In our study, 9 patients (7.14\%) of TLH were given post-op blood transfusion whereas 25 patients of TAH received blood postoperatively and this difference was found statistically significant.

8 patients with TLH were converted to laparotomy in our study. Out of these 8 patients, 5 patients had dense adhesions, 2 patients had vascular injury and 1 patient has bowel injury. While in study by Kanmani et al, only 1 patient with TLH was converted to laparotomy because of dense adhesions. ${ }^{11}$

In our study the incidence of complications in TLH group was $5.5 \%$ and $13.5 \%$ in TAH group. The incidence of major complications in TLH group was $3 \%$ and it was $1.6 \%$ in TAH group. Among major complications in TLH group, 1 patient had bladder injury (managed 
laparoscopically), 1 patient had bowel injury and 2 had vascular injury (conversion to laparotomy was done). Minor post-operative complications in TLH group were $2.4 \%$ versus $8.7 \%$ in TAH group. In TLH group 1 patient had ileus, 1 had febrile morbidity and in 1 patient secondary haemorrhage occurred which was managed conservatively and no blood transfusion was given. While in TAH group febrile morbidity, ileus and wound infection occurred. 4 patients had wound dehiscence for which resuturing was done. The difference between intraoperative complications was insignificant whereas difference observed in post-operative complications was statistically significant. In study by Kanmani et al, the complications in regard to organ injury in TLH was $5.5 \%$, which were not significantly different from TAH group. ${ }^{11}$ Pernio et al, observed $3.9 \%$ complications in TLH group and $10.5 \%$ in TAH group. ${ }^{12}$

It was seen that $64 \%$ of the patients of TLH group were discharged within 3 days while only $8 \%$ of TAH group were discharged within 3 days. Mean duration of hospital stay for TLH group was significantly shorter as compared to TAH group $(3.38 \pm 1.71$ days in TLH group versus $7.52 \pm 3.35$ days in TAH group). Kanmani $\mathrm{M}$ et al in their study also reported the same findings. ${ }^{11}$ In their study mean duration of hospital stay after TLH was 3 days compared with 6 days after TAH. Shrestha et al and Perino et al also reported similar findings. ${ }^{10,12}$

\section{CONCLUSION}

This study showed that TLH can be safely performed by the experienced surgeon as an alternative to abdominal hysterectomy. Up-to-date knowledge of TLH procedure provides good outcome, although it takes longer operative time and higher cost. It offers several benefits over TAH such as smaller incision, earlier ambulation, shorter hospital stay, faster recovery time and does not increase incidence of more serious complications than TAH.

Funding: No funding sources

Conflict of interest: None declared

Ethical approval: The study was approved by the Institutional Ethics Committee

\section{REFERENCES}

1. Weber AM, Lee JC. Use of alternative technique of hysterectomy in Ohio, 1988-1994. New Eng J Med.1996;335(7):438-9.

2. Mazona R, Busaca M, Zupi E. laparoscopically assisted vaginal hysterectomy versus total abdominal hysterectomy: a prospective, randomized, multicentre study. Am J Obstet Gynecol. 1999;180(1):270-5.

3. Cracken GMc, Hunter D, Morgan D. comparision of laparoscopic assisted vaginal hysterectomy, total abdominal hysterectomy and vaginal hysterectomy. Ulster Med J. 2006;75(1):54-8.

4. Garry R, Fountain J, Brown J. Evaluate hysterectomy trial: a multicentre randomized trial comparing abdominal, vaginal and laparoscopic methods of hysterectomy. Health Technol Assess. 2004;8(26):1154.

5. Makinen J, Johansson J, Tomas C. Morbidity of 10110 hysterectomies by type of approach. Hum Reprod. 2001;16(7):1473-8.

6. Sutton C. Hysterectomy: a historical operative. Clin Obstet Gynecol. 1997;11(1):1-22.

7. Kluivers KB, Johnson NP, Chien P. Comparison of laparoscopic and abdominal hysterectomy in terms of quality of life: a systematic review. Eur J Obstet Gynecol Reprod Biol. 2008;136(1):3-8.

8. Walsh CA, Walsh SR, Tang TY. Total abdominal hysterectomy versus total laparoscopic hysterectomy for benign disease: a meta analysis. Eur J Obstet Gynecol Reprod Biol. 2009;144(1):3-7.

9. Loh $\mathrm{FH}$, Canis $\mathrm{M}, \mathrm{Ng}$ SC. laparoscopic hysterectomy- A step forward. Singaport Med J. 1995;36;197-203.

10. Shrestha R, Yu LH. Comparison between laparoscopic hysterectomy and abdominal hysterectomy. NJOG. 2014;17(1):26-8.

11. Kanmani M, Govindarajan M, Selvaraj V. Comparative study of surgical results between total abdominal hysterectomy and total laparoscopic hysterectomy in a tertiary hospital: a 2 year retrospective study. Int $\mathbf{J}$ Reprod Contracept Obstet Gynecol. 2018;7(3):1019-23.

12. Pernio A, Cucinella G, Venezia R. Total laparoscopic hysterectomy versus total abdominal hysterectomy: an assessment of learning curve in prospective randomized study. Hum Reprod. 1999;14:2996-09.

13. Marana R, Busacca M, Zupi F. Laparoscopically assisted vaginal hysterectomy versus Total abdominal hysterectomy. A prospective, randomized multicentre study. Am J Obstet Gynecol. 1999;180:270-5.

Cite this article as: Dogra A, Kumar V, Bhushan N. TLH versus TAH: a 2 year retrospective comparative study. Int J Reprod Contracept Obstet Gynecol 2019;8:3939-42. 